\title{
Demonstration of the temporal evolution of serum markers of skeletal muscle ischaemia reperfusion injury - An observational clinical study.
}

THUSHAN DHANANJA GOONERATNE ( $\boldsymbol{\nabla}$ thushey@hotmail.com )

University of Colombo Postgraduate Institute of Medicine https://orcid.org/0000-0003-2072-4586

Shervanthi Homer-Vanniasinkam

Leeds General Infirmary

Serosha Mandika Wijeyaratne

University of Colombo Faculty of Medicine

\section{Research note}

Keywords: Skeletal muscle, Ischemia-reperfusion injury, temporal evolution, markers

Posted Date: March 3rd, 2020

DOI: https://doi.org/10.21203/rs.3.rs-15764/v1

License: (c) (i) This work is licensed under a Creative Commons Attribution 4.0 International License.

Read Full License 


\section{Abstract}

Objective The study aimed to investigate the temporal evolution of markers of skeletal muscle ischaemia reperfusion injury (IRI) to shed more light into its pathogenesis towards finding a clinical therapeutic intervention. P-selectin, Myeloperoxidase and TNF-alpha were selected as markers of IRI based on their role in its pathogenesis. An observational study was conducted on patients with skeletal muscle ischaemia requiring revascularization. Loco-regional venous sampling was performed at $0,+2,+4,+6$, +12 and +24 hours post-reperfusion to demonstrate the temporal evolution of surrogate markers of IRI.

Results Levels of P-Selectin, Myeloperoxidase and TNF-alpha demonstrated a significant peak elevation during $2 \mathrm{~h}$ - $4 \mathrm{~h}$ following reperfusion when compared to baseline values. (P-selectin $59.48 \mathrm{pg} / \mathrm{ml}$ to $125.91 \mathrm{pg} / \mathrm{ml}, \mathrm{p}=0.008$; Myeloperoxidase $78.84 \mathrm{pg} / \mathrm{ml}$ to $116.86 \mathrm{pg} / \mathrm{ml}, \mathrm{p}=0.051 ;$ TNF-alpha $1.80 \mathrm{pg} / \mathrm{ml}$ to $34.53 \mathrm{pg} / \mathrm{ml}, \mathrm{p}=0.002$ ) All three markers gradually subsided with time and reached baseline pre-perfusion values between $6 \mathrm{~h}-8 \mathrm{~h}$ from time of reperfusion. The study suggests that skeletal muscle IRI in humans is associated with an early exaggerated pro-inflammatory response, as supported by increased expression of reperfusion injury markers in the venous effluent. They demonstrate potential for use as markers of IRI for future clinical trials.

\section{Introduction}

Acute limb ischemia remains one of the most common peripheral vascular emergencies and its management continues to pose significant challenges ${ }^{1}$. The immediate and full restoration of blood flow paradoxically aggravates previous ischemic damage by setting into motion, a host of inflammatory responses that promote local tissue destruction ${ }^{2}$. The systemic washout of resulting toxic metabolites lead to life-threatening systemic complications, including renal, cardiac, and pulmonary failure ${ }^{3}$.

The pathogenesis of skeletal muscle ischaemia reperfusion injury(IRI) is multifactorial, and not completely unravelled. Accumulation of hypoxanthine, imbalance of calcium homeostasis, no-reflow phenomenon, increased leucocyte activation has been suggested. Amongst these the polymorphonuclear leukocyte-endothelial interaction forms an integral component. Leukocyte activation is a multistep process involving rolling, firm adhesion and transmigration mediated by a complex interaction of cell adhesion molecules ${ }^{4}$. Once activated, the neutrophils release highly toxic reactive oxygen species, resulting in cellular damage ${ }^{5}$.

The systematic search for serological markers of skeletal muscle ischemia reperfusion has identified the leucocyte-endothelial interaction as a key step in its pathogenesis, with potential targets for therapeutic interventions. TNF-alpha, Myeloperoxidase (MPO) and soluble P-Selectin are highly sensitive surrogate markers of IRI that are involved in the enhanced leucocyte activity and pro-inflammatory pathogenesis. However, despite the strong preclinical data on neutrophil-endothelial blockade, this success hasn't yet translated to a clinically valid outcome. To the best of our knowledge there are no studies to-date that have attempted to establish whether these markers of reperfusion injury actually do increase following 
reperfusion of ischaemic skeletal muscle in a clinical setting. Nor do we have any evidence to suggest the timeframe that these markers are observed in the reperfusate.

The identification of the temporal evolution of highly sensitive surrogate markers of skeletal muscle IRI will shed more light into dissecting the pathogenesis of IRI and would be essential towards finding a clinical therapeutic intervention.

The study involves, demonstration of the temporal evolution of P-Selectin, myeloperoxidase and TNFalpha in the venous effluent following reperfusion.

\section{Main Text}

\section{Selection of markers of reperfusion injury}

P-Selectin, Myeloperoxidase and TNF-alpha denote key elements in endothelial-leukocyte interaction, polymorphonuclear leukocyte activity, and pro-inflammatory status during IRI.

P-Selectin, a member of the adhesion molecule family expressed in platelets and endothelial cells, is up regulated during IRI and mediates the initial adhesion of leucocytes to the surface of the endothelium, i.e 'leucocyte rolling'. Adhered leucoyctes transmigrate through the endothelium and are activated ${ }^{6,7}$. Leucocytes thus activated release myeloperoxidase. MPO catalyzes the formation of hypochlorite and reactive oxygen species during reperfusion of ischaemic tissue.

TNF-alpha is a pro-inflammatory cytokine released by a variety of cells under stressful conditions. Colletti et al first reported the role of TNF-alpha in IRI in 1990, in a murine model subjected to hepatic ischaemia reperfusion ${ }^{8}$. Subsequent studies have demonstrated that TNF-alpha increases the expression of many cell adhesion molecules as well as releases many cytokines leading to further exaggeration of the neutrophil activation process.

The role of P-selectin and myeloperoxidase during IRI in skeletal muscle has been demonstrated in animal models. Singbarti et al demonstrated the attenuation of IRI-induced acute renal failure in Pselectin deficient mice ${ }^{9}$. Jin-Lian Chen et al demonstrated reduced hepatic/renal insufficiency in mice treated with P-selectin blocking Tetramethylpyrazine ${ }^{10}$. Li et al demonstrated the protective effects of Phloroglucinol, a MPO inhibitor, against myocardial IRI in rats ${ }^{11}$. Preclinical models have supported the hypothesis that local skeletal muscle IRI is mediated in part by TNF-alpha. Studies of Seekamp et al, reported that abrogating TNF-alpha activity with a soluble TNF receptor construct and an anti-TNF-alpha antibody, decreased muscle capillary permeability after IRI in skeletal muscle ${ }^{12}$.

We therefore postulate that P-selectin, Myeloperoxidase and TNF-alpha are suitable markers of reperfusion injury in skeletal muscle ischaemia reperfusion injury in a clinical setting.

\section{Methodology}


An observational study was carried out on patients admitted to the University of Colombo, Vascular Unit at the National Hospital of Sri Lanka with acute lower limb arterial occlusion requiring revascularization.

Patients for whom amputation rather than revascularization was indicated and patients below the age of 18 years, were excluded. A peripheral venous sample was obtained immediately prior to surgery as baseline. Prior to revascularization an indwelling femoral venous catheter was inserted and placed for a period of 24 hours for sampling the venous effluent. Subsequently, loco-regional venous sampling was done using the indwelling femoral venous catheter at $0,+2,+4,+6,+12$ and +24 hours post-reperfusion to establish a temporal evolution of the reperfusion injury markers in the venous effluent.

Loco-regional venous sampling with an indwelling venous catheter as opposed to peripheral venous sampling for 24 hours has been shown to be safe and advantageous during previous studies. Rowlands $\mathrm{T}$ et $\mathrm{al}^{13}$ used femoral vein catheter blood sampling to study lower extremity ischaemia during abdominal aortic aneurysm repair and Wijeyaratne SM et al ${ }^{14}$ used jugular venous catheter blood sampling to study cerebral ischaemia during carotid clamping for endarterectomy.

\section{Assay Methodology}

All laboratory procedures including assaying and analysis of samples were conducted at the Department of Biochemistry, Faculty of Medicine, Colombo.

Serum concentrations of soluble P-selectin and myeloperoxidase were measured by a quantitative sandwich immunoassay technique using an enzyme-linked immunosorbent assay kit (R\&D systems, Minneapolis, MN). Whilst Tumour Necrosis Factor-alpha was assayed in the venous effluent using an immunometric enzyme immunoassay technique (Cayman chemical company, Ann Arbot,MI)

All samples, controls and standards were assayed in triplicate to increase the rigor of the study.

\section{Results}

8 patients were recruited to the study. Patient and disease characteristics are depicted in Table 1 . The average age was 65.8 years. 6 males and 2 females were recruited. 5 patients presented with acute lower limb arterial occlusion due to thromboembolism, whilst 3 underwent clamp induced ischaemia for lower limb revascularization and aortic aneurysm repairs.

The mean levels of P-Selectin, MPO and TNF-alpha at varied time intervals are depicted in Table 2.

There was a significant increase in P-selectin level over the time frame, reaching a peak mean value of $125.91 \mathrm{pg} / \mathrm{ml}$ at the 2 hour interval. Subsequently, P-selectin reached baseline pre-perfusion values within 6-8 hours of reperfusion. The difference between the baseline and the 2 hour values of P-Selectin level was statistically significant $(p=0.008)$. MPO too demonstrated a significant increase over the time frame, reaching a peak mean value of $113.35 \mathrm{pg} / \mathrm{ml}$ at the 2 hour interval $(p=0.051)$, and subsequently reached baseline pre-perfusion values within 8 hours of reperfusion. TNF alpha demonstrated a similar 
pattern with a significant increase at the 2 hour period $(p=0.002)$. Subsequently, levels reached baseline pre-perfusion values within 6 hours of reperfusion.

Immediate post-operative clinical outcome of the patients are depicted in Table 3. This included 1 mortality, subsequent to myocardial ischemia / arrhythmia. Significant morbidities included; below-knee amputation in one patient; evidence of acute tubular necrosis with reduction of urine output and transient elevation in creatinine in one patient. One patient demonstrated development of compartment syndrome. However symptoms resolved with conservative measures and thus did not require fasciotomy.

\section{Discussion}

It is proposed that microvascular injury upon reperfusion of ischaemic tissue is initiated by the reintroduction of molecular oxygen with subsequent production of the toxic hydroxyl ion ${ }^{15}$. The generation of toxic oxygen free radicals overwhelms the anti-oxidant defenses in the tissue leading to oxidative cell damage. Together with an increase in calcium influx, this results in increased membrane permeability ${ }^{16}$, chemo-attraction ${ }^{17}$, an increase in endothelial cell adhesiveness ( via increased expression of cell adhesion molecules such as Selectin ${ }^{18}$ and an activation of leukocytes. Sequestrated activated neutrophils, using their destructive capabilities, act on re-perfused muscle cells leading to further cell damage ${ }^{15}$.

The final endpoint of this process is local tissue injury, resulting in additional skeletal muscle death with compartment syndrome, and post ischaemic syndrome owing to the release of metabolites to the systemic circulation ${ }^{19}$.

P-selectin is one of three structural families of adhesion molecules that is responsible for leukocyte adhesion, penetration of the vessel wall, and trans-endothelial migration into tissue ${ }^{20}$. Myeloperoxidase, an enzyme present in leukocytes, is a marker of tissue leukocyte activity and infiltration ${ }^{21}$. Both P-selectin and Myeloperoxidase levels were elevated in the venous effluent following reperfusion of skeletal muscle. A peak level was noted at $2 \mathrm{~h}-4 \mathrm{~h}$ after reperfusion, before it gradually subsided after $6 \mathrm{~h}-8$ hours. The results confirm the exaggeration of endothelial-leukocyte interaction and subsequent leukocyte activation in human skeletal muscle reperfusion injury.

Tumor necrosis factor is an inflammatory cytokine that is expressed by macrophages and other tissue early during ischemia-reperfusion injury ${ }^{22}$. Unlike the two previous markers, the role of TNF-alpha in skeletal muscle reperfusion injury is controversial. While some groups report beneficial effects, others find a detrimental role ${ }^{23}$.

TNF-alpha clearly initiates expression of an entire spectrum of inflammatory cytokines that is crucial towards activation of neutrophils as well as the complement cascade. Levels of TNF-alpha in the venous effluent increased dramatically on reperfusion, with a peak value at two hours after blood flow was restored. Results affirm, that lower extremity-reperfusion in humans is associated with an exaggerated 
inflammatory response, as supported by increased expression TNF alpha, P-Selectin and Myeloperoxidase in the venous effluent.

The results of the study, have demonstrated that lower extremity-reperfusion in humans is associated with an exaggerated inflammatory response, as supported by increased expression of soluble P-selectin , myeloperoxidase and TNF alpha in the venous effluent. This is the first clinical study to demonstrate the temporal evolution of these markers in the venous effluent after skeletal muscle ischaemia reperfusion injury. Whilst their utility as a diagnostic tool is limited, they reflect injury severity and potential for use as markers of IRI in a more robust clinical trial.

\section{Limitations}

Our study has several limitations. There was heterogeneity in the patient population with patients with both thromboembolism induced and clamp-induced acute lower limb arterial occlusions included in the study. This is reflected in the variation of baseline levels of the surrogate markers. The three markers reflect key steps in the pathogenesis of IRI, but remain indirect evidence. We were unable to obtain consent for immunohistochemical assessment of skeletal muscle to correlate with the temporal evolution of markers. Having histological samples would have aided in understanding the disease pathogenesis better.

\section{Abbreviations}

IRI - Ischaemia - Reperfusion Injury

TNF - Tumour necrosis factor

MPO - Myeloperoxidase

\section{Declarations}

\section{Acknowledgements}

The authors thank the Department of Biochemistry, Faculty of Medicine for helping with laboratory work.

\section{Authors' contributions}

Study design: TDG, SMW, SHV. Drafting of study protocol: TDG, SMW, SHV. Sample collection and laboratory analysis: TDG. Statistical analysis: TDG Interpretation of results: TDG, SMW, SHV. Writing of the manuscript: TDG, SMW, SHV. manuscript: FA, MD and RP. All authors read and approved the final manuscript.

\section{Funding}


No external funding was utilized for the study.

\section{Availability of data and materials}

All data generated or analysed during this study are included in this published article.

\section{Ethics approval and consent to participate}

The study was carried out in keeping with the guidelines approved by the Ethical review committee of the Faculty of medicine, University of Colombo. (ref no EC-11-166). Informed, written consent was obtained from all participants prior to inclusion in the study.

\section{Consent for publication}

Not applicable.

\section{Competing interests}

The authors declare that they have no competing interests

\section{References}

1. Dhaliwal G, Mukherjee D. Peripheral arterial diease: Epidemiology, natural history, diagnosis and treatment. Int J Angiol. 2007summer;16(2):36-44

2. Blaisdell FW. The pathophysiology of skeletal muscle ischemia and the reperfusion syndrome: a review. Cardiovasc Surg. 2002;10:620-630.

3. Carden DL, Granger DN. Pathophysiology of ischaemia-reperfusion injury. J Pathol. 2000;190:255266.

4. Colgan SP, Dzus AL, Parkos CA. Epithelial exposure to hypoxia modulates neutrophil transepithelial migration. J Exp Med. 1996; 184:1003-1015.

5. Harlan JM. Leucocyte-endothelial interactions. Blood 1985; 65:513-25.

6. Ilwabuchi K, Nagaoka I, Yamashita T. Modulation of neutrophil adherence to endothelial cells by platelet-derived adherence-inhibiting factor through interactions with selectin molecules. J. leukoc.Biol. 1998;63:500-508.

7. Koedam JA, Cramer EM, Briend E, Furie BC, Wagner DD. P-Selectin, A granule membrane protein of platelets and endothelial cells, follow the regulated secretory pathway in AtT-20 cells. J Cell Biol.1992 Feb;116(3):617-25.

8. Colletti LM, Remick DG, Burtch GD, Role of tumor necrosis factor-alpha in the pathophysiologic alterations after hepatic ischemia/reperfusion injury in the rat. J Clin Invest. 1990;85:1936-1943

9. Singbarti K, Green SA, Ley K. Blocking P-selectin protects from ischaemia / reperfusion-induced acute renal failure. FASEB J. 2000 Jan;14(1):48-54 
10. Chen JL, Zhou T, Chen WX, et al. Effect of tetramethylpyrazine on P-selectin and hepatic/renal ischemia and reperfusion injury in rats. World J Gastroenterol. 2003;9(7):1563-1566

11. Li TT, Zhang YS, He L, Li NS, Peng J, Li YJ. Protective effect of phloroglucinol against myocardial ischaemia-reperfusion injury is related to inhibition of myeloperoxidase activity and inflammatory cell infiltration. Clinincal and Experimental Pharmacology and Physiology 2011 Jan; 38(1):27-33.

12. Seekamp A, Warren JS, Remick DG, Till GO, Ward PA. Requirements for tumor necrosis factor-alpha and interleukin-1 in limb ischemia/reperfusion injury and associated lung injury. Am. J. Pathol. 1993 Aug; 143(2): 453-463.

13. E Rowlands, S Homer-Vanniasinkam. Pro- and anti-inflammatory cytokine release in open versus endovascular repair of AAA. Br J Surg.2001;88:1335-1340

14. Wijeyaratne SM, Collins MA, Barth JH, Gough MJ. Jugular Venous Neurone Specific Enolase (NSE) Increases Following Carotid Endarterectomy Under General, but Not Local, Anaesthesia. Eur J Vasc Endovasc Surg. 2009;38:262-266.

15. Kalogeris T, Baines CP, Krenz M, Korthuis RJ. Cell biology of ischaemia-reperfusion injury. Int Rev Cell Mol Biol. 2012;298:229-317

16. Duran, WN, Milazzo VJ, Sabido F, Robert WH. Platelet-activating factor modulates leukocyte adhesion to endothelium in ischaemia-reperfusion injury. Microvasc Res. 1996 Jan;51(1):108-115

17. Walter N. Duran, Peter J. Pappas, Mauricio P. Boric, Robert W. Hobson II. Pathophysiology of Skeletal Muscle Ischemia-Reperfusion Injury. Haimovici's Vascular Surgery by Ascher, Enrico

18. Filho RD, de Sousa MMR, Silva JCCB, Gabriel A, Uilan M, Miranda F, Burihan E. Blockage of intercellular adhesion molecule-1(ICAM-1) in the prevention of reperfusion lesion in the skeletal musculature of EPM-1 Wisatar rats. Physiol. 1997;1323-1328.

19. Ljungman C, Holmberg L, Bergqvist D, Bergstrom R, Adami HO. Amputation risk and survival after embolectomy for acute arterial ischaemia: time trends in a defined Swedish population. Eur J Vasc Endovasc Surg. 1996;11:176-182.

20. Kyriakides C, Woodcock SA, Wang Y et al. Soluble P-Selectin moderated complement-dependent reperfusion injury of ischaemia skeletal musle. Am J Physiol Cell Physiol. 2000 Aug: 279(2): C520-8

21. Lau D, Mollnau H, Eiserich JP et al. Myeloperoxidase mediates neutrophil activation by association with CD11b/CD18 integrins. Proc Natl Acad Sci USA. 2005;102:431-436.

22. Souza DG, Soares AC, Pinho V et al. Increased mortality and inflammation in tumour necrosis factorstimualted gene- 14 transgenic mice after ischaemia and reperfusion injury. Am J Pathol. 2002 May; 160(5): 1755-1765.

23. Duran WN. The double edge sword of TNF-alpha in ischaemia- reperfusion injury. Am J Phyiol Heart Circ Physiol. 2008 Dec; 295(6):H2242-9.

\section{Tables}


Table 1 - Patient and disease characteristics of the study participants

\begin{tabular}{|c|c|c|c|c|c|}
\hline $\begin{array}{c}\text { Age } \\
\text { (range) }\end{array}$ & Sex & Type of surgery & $\begin{array}{c}\text { Rutherford } \\
\text { stage }\end{array}$ & $\begin{array}{c}\text { Level of } \\
\text { ischaemia }\end{array}$ & $\begin{array}{l}\text { Ischaemic } \\
\text { time (min) }\end{array}$ \\
\hline $70-80$ & Female & Clamp induced & - & $\begin{array}{c}\text { Abdominal } \\
\text { aorta }\end{array}$ & 75 \\
\hline $70-80$ & Male & Thromboembolism & IIa & Femoral & 315 \\
\hline $60-70$ & Male & Thromboembolism & - & Femoral & 125 \\
\hline $40-50$ & Male & Thromboembolism & IIb & Femoral & 105 \\
\hline $60-70$ & Male & Thromboembolism & IIb & Femoral & 180 \\
\hline $70-80$ & Male & Clamp induced & - & Aorta & 150 \\
\hline $80-90$ & Male & Clamp induced & - & Aorta & 90 \\
\hline $50-60$ & Female & Thromboembolism & IIb & Femoral & 320 \\
\hline
\end{tabular}

Rutherford IIa - Acute limb ischaemia with threatened viability but marginal ; Rutherford IIb - Acute limb ischaemia with threatened viability requiring immeadiate revascularization

Table 2 - Temporal evolution of reperfusion injury marker in the venous effluent (data mean $(\mathrm{pg} / \mathrm{ml})+/-$ SEM)

\begin{tabular}{lcccccc}
$\begin{array}{l}\text { Reperfusion } \\
\text { injury marker }\end{array}$ & Baseline & +2 hours & +4 hours & +6 hours & +12 hours & +24 hours \\
\hline P-Selectin & $59.4+/-11.2$ & $125.9+/-20.6^{*}$ & $63.2+/-11.8^{*}$ & $44.1+/-13.1$ & $16.2+/-4.3$ & $5.8+/-2.5$ \\
Myeloperoxidase & $78.8+/-16.4$ & $113.3+/-3.6^{*}$ & $92.1+/-13.1^{*}$ & $55.1+/-4.2$ & $33.8+/-6.9$ & $10.7+/-0.9$ \\
TNF-alpha & $2.2+/-1.4$ & $31.2+/-12.7^{*}$ & $19.2+/-7.6^{*}$ & $5.2+/-2.3$ & $2.1+/-0.8$ & $0.6+/-0.2$
\end{tabular}

* p values $<0.05$ on dependent T-test

Table 3 - Early post-operative outcome following reperfusion after skeletal muscle ischaemia among study participants 


\begin{tabular}{|c|c|c|c|c|}
\hline $\begin{array}{c}\text { Age } \\
\text { range }\end{array}$ & Sex & Type of surgery & $\begin{array}{l}\text { Level of } \\
\text { ischaemia }\end{array}$ & Outcome \\
\hline $\begin{array}{l}70- \\
80\end{array}$ & Female & Clamp induced & $\begin{array}{l}\text { Abdominal } \\
\text { aorta }\end{array}$ & $\begin{array}{l}\text { Death - MI / } \\
\text { Arrhythmia }\end{array}$ \\
\hline $\begin{array}{l}70- \\
80\end{array}$ & Male & Thromboembolism & Femoral & $\begin{array}{c}\text { Normal limb function, } \\
\text { but transient drop in } \\
\text { UOP }\end{array}$ \\
\hline $\begin{array}{c}60- \\
70\end{array}$ & Male & Thromboembolism & Femoral & Normal \\
\hline $\begin{array}{c}40- \\
50\end{array}$ & Male & Thromboembolism & Femoral & $\begin{array}{c}\text { Compartment } \\
\text { syndrome }\end{array}$ \\
\hline $\begin{array}{c}60- \\
70\end{array}$ & Male & Thromboembolism & Femoral & Normal \\
\hline $\begin{array}{l}70- \\
80\end{array}$ & Male & Clamp induced & Aorta & Normal \\
\hline $\begin{array}{c}80- \\
90\end{array}$ & Male & Clamp induced & Aorta & Normal \\
\hline $\begin{array}{l}50- \\
60\end{array}$ & Female & Thromboembolism & Femoral & Amputation BK \\
\hline
\end{tabular}

MI - myocardial infarction; UOP - Urine out put; BK - below knee amputation

\section{Supplementary Files}

This is a list of supplementary files associated with this preprint. Click to download.

- datasheet.docx 